\title{
STRATEGI PENINGKATAN PROGRAM EMPLOYEE ENGAGEMENT DI TELKOM UNIVERSITY DENGAN MENGGUNAKAN METODE ADDIE
}

\author{
Farah Fadhila Mulyadi", Christanto Triwibisono, Ima Normalia Kusmayanti \\ Program Studi Teknik Industri, Fakultas Rekayasa Industri, Universitas Telkom \\ Email: farah.mulyadi@gmail.com; christanto@telkomuniversity.ac.id; kusmayanti.1982@gmail.com \\ Artikel masuk : 27-07-2020 \\ Artikel direvisi : 20-11-2020 \\ Artikel diterima : 01-12-2020 \\ *Penulis Korespondensi
}

\begin{abstract}
Abstrak -- Telkom University merupakan perguruan tinggi swasta dibawah naungan Yayasan Pendidikan Telkom. Menjadi perguruan tinggi swasta terbaik tidak terlepas dari peranan karyawan Telkom University, termasuk dosen. Kondisi aktual saat ini diketahui bahwa di Telkom University sebelumnya tidak pernah melakukan pengukuran terkait dengan employee engagement. Semangat, antusiasme dan usaha yang tinggi yang ditunjukkan karyawan, merupakan bagian dari dampak employee engagement yang ditunjukkan karyawan. Untuk itu perlu dilakukan analisis dan pengukuran terkait dengan tingkat employee engagement dengan menggunakan 5 dimensi yang dikembangkan Triwibisono. Pada penelitian ini alat ukur yang digunakan adalah 5 dimensi employee engagement yang dikembangkan oleh Triwibisono dan rancangan program dengan menggunakan metode ADDIE dengan respondennya adalah Dosen Tetap yang ada di Telkom University. Dari hasil pengukuran terhadap 70 responden, yang ditentukan dengan menggunakan teknik purposive sampling, dengan kategori dosen tetap di Telkom University, diketahui bahwa tingkat engagement di Telkom University adalah sebesar $34 \%$ untuk kategori engaged, 66\% untuk kategori not engaged dan 0\% untuk kategori actively disengaged. Perancangan dipilih berdasarkan dimensi yang memiliki nilai terendah, yaitu Basic need, Spirit dan meaningfulness. Dimensi basic need dengan membuat survei kebutuhan dan pembuatan format standar untuk identifikasi kebutuhan. Pada dimensi spirit dengan memberikan penghargaan sebagai bentuk apresiasi bagi dosen yang bekerja dalam waktu yang lama. Dimensi meaningfulness dengan memberikan pelatihan terkait value openness yang sudah ada di Telkom University.
\end{abstract}

Kata kunci: Metode ADDIE; Employee Engagement; Basic Need; Spirit; Meaningfulness

\begin{abstract}
Telkom University is a private university under the auspices of the Telkom Education Foundation. Being the best private university cannot be separated from Telkom University employees' roles, including lecturers. The current condition shows that Telkom University has never previously taken measurements related to employee engagement. The excitement, confidence, and increased action shown by employees are part of the impact of employee engagement shown by employees. For this reason, it is necessary to carry out analysis and measurement related to the level of employee engagement using the five dimensions developed by Triwibisono. In this study, the measuring instruments used were five dimensions of employee engagement developed by Triwibisono and program design using the ADDIE method. The respondents were permanent lecturers at Telkom University. From the measurement results of 70 respondents, which were determined using purposive sampling technique, with the category of permanent lecturers at Telkom University, it is known that the level of engagement at Telkom University is 34\% for the engaged category, $66 \%$ for the not engaged category and $0 \%$ for the actively disengaged type. The design is chosen based on the dimensions with the lowest value: Basic need, Spirit, and meaningfulness. The basic need dimension is by making a needs survey and making a standard format for identifying needs, in the spirit dimension, giving awards as a form of appreciation for lecturers who work for a long time. The dimension of meaningfulness by providing training related to value openness that already exists at Telkom University.
\end{abstract}

Keywords: ADDIE Method; Employee Engagement; Basic Need; Spirit; Meaningfulness 


\section{PENDAHULUAN}

Pengelolaan sumber daya manusia yang baik akan berdampak kepada kualitas kerja karyawan. Employee engagement merupakan sarana yang menyelaraskan antara tujuan karyawan dengan tujuan dari organisasi tersebut (Albrech, 2011). Sumber daya pekerjaan mengacu pekerjaan secara positif mempengaruhi prestasi kerja, kesejahteraan fisik dan psikologis, serta pembelajaran dan pertumbuhan karyawan (Hobfoll, 2001). Sebaliknya, tuntutan pekerjaan mengacu pada karakteristik terkait pekerjaan yang membutuhkan fisik dan psikologis yang signifikan investasi dan jika berlebihan, menghambat hasil kinerja (Kwon \& Kim, 2020). Sementara itu, ada beberapa studi mengklaim bahwa sebuah organisasi atau perusahaan yang memiliki tingkat engagement yang tinggi, maka perusahaan atau organisasi tersebut memiliki tingkat kinerja organisasi yang lebih baik (Rawling, 2015).Studi Harvard Business Review menunjukkan $71 \%$ orang berpendapat bahwa keterlibatan karyawan yang efektif sangat penting untuk keberhasilan setiap organisasi (Kaliannan \& Adjovu, 2015). Keterlibatan aktif tenaga kerja mampu meningkatkan motivasi bekerja (Mehta \& Mehta, 2013), kemampuan beradaptasi (Kumar, 2012) yang berdampak pada pengurangan biaya perekrutan dan retensi, peningkatan inovasi, berdampak positif pada keuntungan, dan peningkatan tingkat produktivitas.

Tingkat nilai kinerja individu dosen di Telkom University yang terbagi menjadi lima tingkatan. Lima tingkatan tersebut terdiri dari P1, P2, P3, P4 dan P5 (Gambar 1). "P" disini memiliki kepanjangan performance, yang melambangkan tingkat kinerja karyawan di perusahaan. Dimana semakin tinggi nilai $P$ memiliki arti kinerja karyawan tersebut tergolong rendah. Dari gambar tersebut, dapat dilihat bahwa kinerja dosen yang paling tinggi ada pada golongan P2. Hal ini dapat diartikan bahwa kinerja dosen Telkom University masih perlu untuk ditingkatkan (Telkom University, 2019).

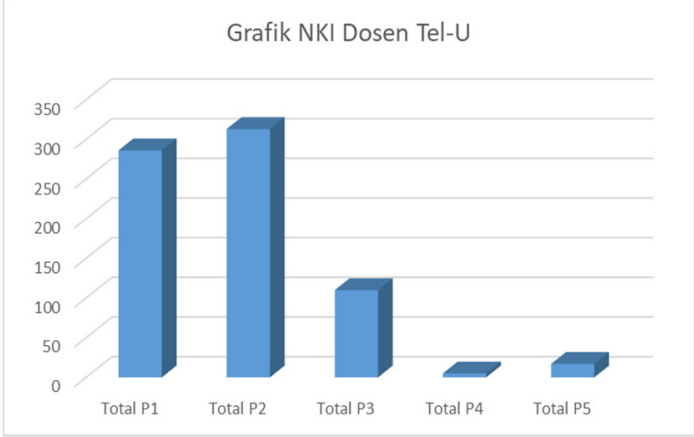

Gambar 1. Grafik NKI Dosen Telkom University
Berdasarkan hasil wawancara dengan salah satu karyawan yang ada pada divisi SDM rektorat Telkom University, dapat diketahui bahwa sebelumnya di Telkom University pengukuran tingkat employee engagement belum pernah dilakukan. Tingkat employee engagement dapat dilihat dari opini publik dan keadaan SDM saat itu. Telkom University sebagai perusahaan juga tidak mengetahui seberapa penting perusahaan bagi karyawannya, sehingga Telkom University tidak memiliki acuan untuk dapat meningkatkan keterlibatan karyawan terhadap perusahaan. Sedangkan jika dibandingkan dengan riset yang dilakukan oleh Gallup, tingkat keterlibatan karyawan di sebuah perusahaan sangat berdampak terhadap kinerja dan produktivitas karyawannya (Adkins, 2014).

Telkom University memiliki karyawan sejumlah 1288 yang terdiri dari 908 Dosen dan 380 TPA, tersebar di tujuh fakultas. Dari 908 Dosen di Telkom University, terbagi kedalam beberapa status yaitu 629 orang Dosen Tetap, 1 orang Dosen Calon Pegawai, 208 orang Dosen full time dan 56 orang Dosen part time. Sedangkan untuk dosen perbantuan, Telkom University memiliki 7 Dosen perbantuan kopertis dan 7 Dosen perbantuan Telkom (Telkom University, 2020). Berdasarkan data tersebut, dapat dilihat bahwa mayoritas karyawan yang ada di Telkom University adalah dosen tetap. Untuk itu, pada penelitian ini menjadikan dosen tetap sebagai subjek penelitian dengan tujuan agar mampu merepresentatifkan hasilnya bagi dosen berstatus lain dan Tenaga Penunjang Akademik.

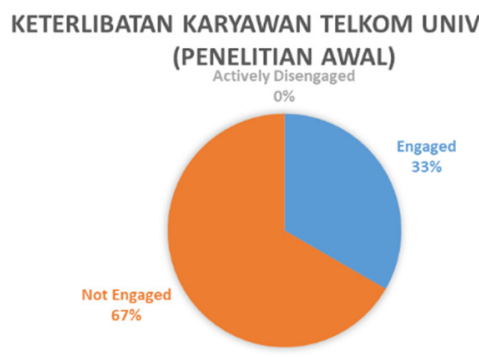

Gambar 2. Grafik Tingkat Keterlibatan Karyawan Telkom University

Penelitian awal terdiri dari 30 responden, dengan $53,33 \%$ responden laki-laki dan $46,67 \%$ responden perempuan yang tersebar di 7 fakultas yang ada di Telkom University. Penelitian awal sebagai gambaran tingkat engagement di Telkom University, yang sebelumnya tidak pernah melakukan survei terkait employee engagement. Saat ini institusi pendidikan membutuhkan karyawan yang terlibat untuk mencapai kinerja 
yang diinginkan oleh perusahaan. Pada penelitian awal dilakukan pengukuran dengan menggunakan dimensi keterlibatan karyawan yang dikembangkan oleh Triwibisono yang terdiri dari lima dimensi. Dimensi tersebut terdiri dari basic need, spirit, meaningfulness, management support dan growth (Triwibisono et al., 2017).

Hasil penelitian awal menunjukkan 33\% dosen terlibat dengan perusahaan dengan kategori engaged, $67 \%$ dosen sedikit terlibat dengan perusahaan dengan kategori not engaged, dan $0 \%$ dosen tidak terlibat sama sekali dengan perusahaan dengan kategori actively disengaged. Hal ini menunjukkan karyawan di Telkom University tidak seluruhnya terlibat dengan baik. Presentasi karyawan tidak terlibat lebih besar daripada yang terlibat. Peningkatan employee engagement dapat mempengaruhi kinerja dan produktivitas karyawan untuk mencapai tujuan perusahaan. Penelitian ini dilakukan untuk merancang program peningkatan employee engagement di Telkom University. Penelitian ini bertujuan untuk mengetahui tingkat keterlibatan karyawan Telkom University. Hasil penelitian diharapkan dapat menjadi acuan Telkom University untuk melakukan pengukuran dan perbaikan yang berhubungan dengan peningkatan employee engagement.

\section{METODE PENELITIAN}

Model konseptual penelitian ini bertujuan untuk memperlihatkan kerangka kerja dalam melakukan penelitian employee engagement berdasarkan dimensi Triwibisono (2017). Pengukuran employee engagement didasari lima dimensi keterlibatan karyawan yang terdiri dari basic need, spirit, meaningfulness, management support dan growth. Selanjutnya dimensi yang dimodelkan ini akan menghitung indeks dari engagement dengan mengelompokan hasil pengukuran engagement sesuai dengan kategori engaged, not engaged dan actively disengaged.

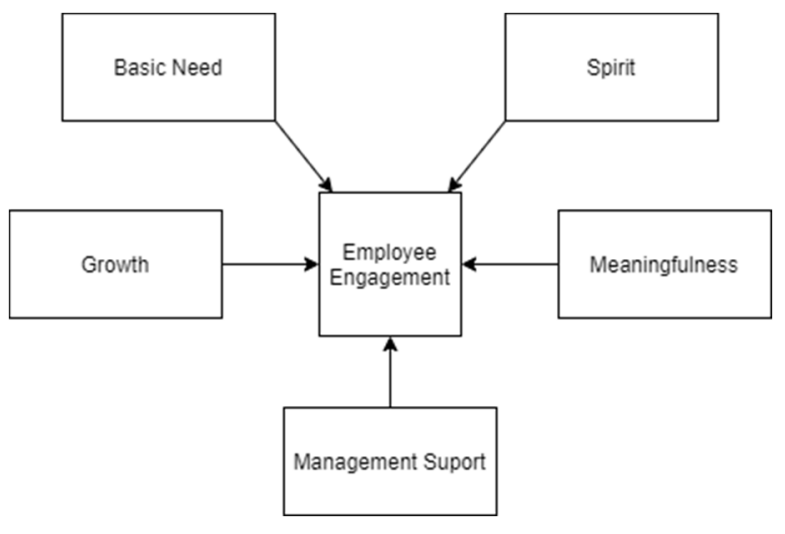

Gambar 3. Model Konseptual
Penelitian ini menggunakan data sekunder berupa profil perusahaan dan nilai kinerja individu dosen dan data primer berupa penyebaran kuesioner dengan menggunakan dimensi keterlibatan Triwibisono. Pemilihan responden dengan menggunakan teknik purposive sampling dengan pertimbangan tertentunya adalah Dosen Tetap. Responden diambil dari 7 fakultas yang ada di Telkom University dengan jumlah 10 responden di setiap fakultas. Kuesioner disebar dan diolah, dengan melakukan verifikasi mengenai dimensi employee engagement yang digunakan apakah sesuai dengan institusi atau tidak. Pada tahap perancangan, dibagi menjadi dua tahapan. Pertama adalah tahapan pengukuran tingkat employee engagement dengan menggunakan kuesioner yang dikembangkan oleh Triwibisono. Kedua adalah merancang program peningkatan employee engagement yang terdiri dari tiga tahapan, analysis, design dan development.

Penelitian ini menggunakan metode ADDIE yang mempunyai lima tahapan, yaitu analysis, design, development, implementation dan evaluation. Model desain instruksional ADDIE merupakan model desain pembelajaran/pelatihan yang bersifat generik menjadi pedoman dalam membangun perangkat dan infrastruktur program pelatihan yang efektif, dinamis dan mendukung kinerja pelatihan itu sendiri (Pargito, 2010). Lima tahap program pengembangan peningkatan employee engagement adalah sebagai berikut:

a. Analisis (Analysis)

Tahap analisis merupakan suatu proses needs assessment (analisis kebutuhan), mengidentifikasi masalah (kebutuhan) dan melakukan analisis tugas (task analyze). Output yang dihasilkan berupa karakteristik atau profil calon peserta didik, identifikasi kebutuhan dan analisis tugas yang rinci didasarkan kebutuhan.

b. Desain (Design)

Tahap ini dikenal dengan istilah membuat rancangan (blue print), ibarat bangunan maka sebelum dibangun harus ada rancang bangun diatas kertas terlebih dahulu.

c. Pengembangan (Development)

Merupakan proses mewujudkan blue print alias desain tadi menjadi kenyataan atau melakukan pengembangan dari desain yang sudah ada. Artinya pada tahap ini segala sesuatu yang dibutuhkan atau yang akan mendukung proses pembelajaran semuanya harus disiapkan.

d. Implementasi (Implementation)

Implementasi adalah langkah nyata untuk menerapkan sistem yang dibuat. Artinya, pada tahap ini semua yang telah dikembangkan 
diset sedemikian rupa sesuai dengan peran atau fungsinya agar bisa diimplementasikan. Setelah siap, maka dapat diuji cobakan melalui kelompok besar kemudian dievaluasi dan direvisi. Kemudian uji coba dapat dilakukan pada kelompok besar kemudian dievaluasi kembali dan direvisi sehingga menghasilkan produk akhir yang siap didiseminasikan.

e. Evaluasi (Evaluation)

Evaluasi adalah proses untuk melihat apakah sistem yang sedang dibangun berhasil, sesuai dengan harapan awal atau tidak. Tahap evaluasi bisa dilakukan pada setiap empat tahap diatas yang disebut evaluasi formatif, karena tujuannya untuk kebutuhan revisi. Misalnya pada tahap rancangan diperlukan review ahli untuk memberikan input terhadap rancangan yang sedang dibuat.

\section{HASIL DAN PEMBAHASAN}

Tingkat employee engagement diukur dengan menyebarkan kuesioner berdasarkan pertanyaan dari dimensi Triwibisono (2017) yang terdiri dari basic need, spirit, meaningfulness, management support dan growth. Sampel dari penelitian ini adalah Dosen Tetap, dikarenakan memiliki jumlah paling banyak dari Dosen berstatus lainnya. Setelah melakukan rekapitulasi kuesioner, selanjutnya dilakukan kategorisasi employee engagement berdasarkan kategori dari Triwibisono agar dapat mengetahui jumlah responden pada setiap kategori (Tabel 1).

Tabel 1 Kategorisasi Employee Engagement (Triwibisono, 2017)

\begin{tabular}{ccc}
\hline Nilai & Tingkat Engagement & Kode \\
\hline $81-100$ & $\begin{array}{c}\text { Engaged } \\
\text { (Terlibat/Terikat) }\end{array}$ & $\mathrm{E}$ \\
$41-80$ & $\begin{array}{c}\text { Not Engaged (Sedikit } \\
\text { Terlibat/Terikat) }\end{array}$ & $\mathrm{NE}$ \\
$20-40$ & $\begin{array}{c}\text { Actively Disengaged } \\
\text { (Tidak Terlibat/Terikat) }\end{array}$ & $\mathrm{AD}$ \\
\hline
\end{tabular}

Selanjutnya untuk dapat menentukan responden masuk kedalam kategori yang mana, maka dilakukan perhitungan dengan melakukan perkalian dan penjumlahan dengan nilai maksimal adalah 100 .

$$
\begin{aligned}
& (2 \times \mathrm{BN})+\left(\frac{3}{4} \times \mathrm{S}\right)+(2 \times \mathrm{MF})+(1 \times \mathrm{MS})+(2 \times \mathrm{G})= \\
& (2 \times(X 1+X 2))+\left(\frac{3}{4} \times(X 3+X 4+X 5)\right)+(2 \times(X 6+X 7))+ \\
& (1 \times(X 8+X 9+X 10+X 11))+(2 \times(X 12+X 13))
\end{aligned}
$$

BN adalah faktor yang pada pada dimensi basic need, S adalah faktor pada dimensi spirit, MF adalah faktor pada dimensi meaningfulness,
MS adalah faktor pada dimensi management support dan $\mathrm{G}$ adalah faktor pada dimensi growth. Sedangkan $\mathrm{Xn}$ melambangkan pertanyaan kedari kuesioner. Contoh cara perhitungan persentase dan nilai indeks untuk seorang responden yang memberikan tanggapan terhadap 13 item pertanyaan adalah sebagai berikut :

$$
\begin{gathered}
(2 \times(4+4))+\left(\frac{3}{4} \times(4+4+3)\right)+(2 \times(4+3))+(1 \times \\
(3+3+3+4))+(2 \times(3+4))=71,67
\end{gathered}
$$

Dengan cara yang sama, dilakukan perhitungan terhadap 70 responden. Hasil perhitungan sebagai dasar pengelompokan kategori employee engagement sehingga diperoleh informasi apakah responden tergolong kategori engaged, not engaged atau actively disengaged (Tabel 2). Perhitungan nilai dimensi dilakukan dengan mengalikan total responden dengan nilai skor tertinggi dari setiap pertanyaan yaitu 5 , kemudian hasil perkalian tersebut dibagi dengan jumlah nilai total seluruh jawaban dari setiap pertanyaan berdasarkan dimensi. Hasil tingkat engagement setiap dimensi, yang terlihat pada Tabel 4, Dapat diketahui bahwa dimensi management support memiliki nilai tertinggi, yaitu $33.62 \%$. Kemudian disusul oleh dimensi growth dengan nilai $33.46 \%$, dimensi meaningfulness $32.89 \%$ dan basic need $32.83 \%$ yang terakhir adalah spirit $32.73 \%$ (Tabel 3).

Tabel 2. Pengelompokan Engagement Responden

\begin{tabular}{ccc}
\hline Kategori & Jumlah (Orang) & Persentase \\
\hline $\mathrm{E}$ & 24 & $34 \%$ \\
$\mathrm{NE}$ & 46 & $66 \%$ \\
$\mathrm{AD}$ & 0 & $0 \%$ \\
\hline
\end{tabular}

Tabel 3. Hasil Perhitungan Tingkat Engagement

\begin{tabular}{lc}
\hline \multicolumn{1}{c}{ Dimensi } & Tingkat Engagement \\
\hline Basic Need & $32.83 \%$ \\
Spirit & $32.77 \%$ \\
Meaningfulness & $32.89 \%$ \\
Management Support & $33.62 \%$ \\
Growth & $33.46 \%$ \\
\hline
\end{tabular}

Tingkat engagement pada faktor-faktor dengan nilai terendah yang ada pada dimensi spirit, meaningfulness dan basic need ditentukan tingkat prioritas kepentingan perancangan program untuk dimensi-dimensi tersebut agar perusahaan dapat menentukan aspek mana yang diutamakan untuk diberi rancangan program peningkatan Employee Engagement. Untuk dimensi basic need, faktor dengan nilai terendah 
adalah material dan peralatan yang dibutuhkan oleh karyawan dan yang diberikan oleh perusahaan. Untuk dimensi spirit, faktor dengan nilai terendah adalah seberapa lama waktu yang diluangkan oleh karyawan untuk bekerja. Sedangkan untuk dimensi meaningfulness, faktor dengan nilai terendah adalah penghargaan dimana pendapat karyawan di tempat kerja di pertimbangkan (Gambar 4).

Faktor Dimensi dengan Nilai Terendah

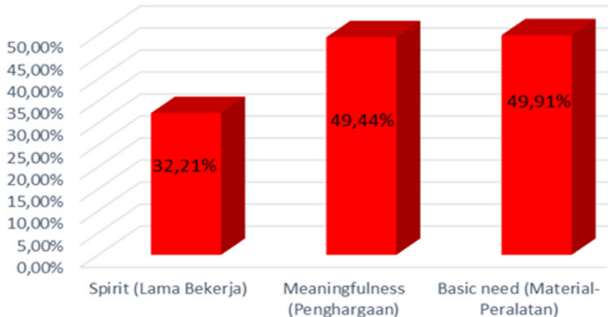

Gambar 4. Faktor dimensi dengan Nilai Terendah

Dimensi basic need yang menjadi perhatian adalah perusahaan menyediakan material dan peralatan bagi dosen terkait pengajaran, tetapi hanya pada material dan peralatan yang standar saja. Setiap fakultas memiliki kebutuhan pengajaran yang berbeda-beda. Seperti Fakultas Industri Kreatif yang mana jurusan pada fakultas ini dalam melakukan praktek dan pengajaran membutuhkan material dan peralatan yang bukan standar seperti material kayu, kain dan lainnya dan kebutuhan ini tidak disediakan institusi secara langsung. Pada dasarnya asisten manajer SDM setiap fakultas sudah melakukan identifikasi kebutuhan, namun belum ada format standar yang dibakukan dalam melakukan identifikasi. Untuk mengatasi permasalahan ini, program yang dirancang adalah dengan membuat survei kebutuhan karyawan yang disesuaikan dengan kebutuhan setiap fakultas. Survei tersebut dapat dilakukan dengan langkah sebagai berikut:

a. Perencanaan Survei

b. Perencanaan Kuesioner

c. Pengadministrasian Kuesioner

d. Penganalisaan Data

e. Pengambilan Tindakan Korektif

Tindakan selanjutnya adalah melakukan identifikasi kebutuhan untuk mengetahui material dan peralatan apa saja yang harus disediakan bagi karyawan dalam bekerja. Untuk mengoptimalkan identifikasi ini dibutuhkan format identifikasi yang standar dan dapat digunakan sebagai tools untuk identifikasi. Dalam melakukan identifikasi perlu memperhatikan hal-hal berikut:

a. Prinsip efisien dan efektif dari material dan peralatan b. Aspek pengadaan berkelanjutan

c. Penilaian prioritas kebutuhan

d. Material dan peralatan yang tersedia

Parameter yang mempunyai nilai rendah pada dimensi spirit adalah di Telkom University, jika dosen melakukan kerja lembur perhitungan kerja lembur bagi dosen tidak ada. Namun untuk saat ini Telkom University menggunakan sistem "Tel-U point Dosen" yang dihitung berdasarkan SKS, namun seperti yang diketahui setiap dosen memiliki minimum SKS yang diemban berbedabeda dan disesuaikan dengan jabatan fungsional dosen. Untuk mengatasi masalah pada faktor bekerja dalam waktu yang lama, perlu dilakukan pengembangan terhadap sistem "Tel-U point Dosen". Program pengembangan atau sistem tambahan yang dilakukan adalah pemberian reward. Pemberian reward dimaksudkan untuk dapat meningkatkan produktivitas dan mempertahankan karyawan yang berprestasi agar tetap berada dalam perusahaan. Dalam memberikan apresiasi, tidak selalu harus dalam bentuk uang namun juga dapat diganti dengan non material seperti promosi jabatan atau penghargaan.

Berdasarkan keputusan menteri tenaga kerja dan transmigrasi Republik Indonesia nomor Kep. 102/MEN/Vl/2004 pasal 4 ayat 2 dan 3, menyatakan bahwa bagi pekerja/buruh yang termasuk dalam golongan jabatan tertentu, tidak berhak atas upah kerja lembur. Dimana golongan jabatan tertentu itu adalah mereka yang memiliki tanggung jawab sebagai pemikir, perencana, pelaksana dan pengendali jalannya perusahaan yang waktu kerjanya tidak dapat dibatasi menurut waktu kerja yang ditetapkan perusahaan sesuai dengan peraturan perundang-undangan yang berlaku (Tenaga Menteri dan Transmigrasi Republik Indonesia, 2004). Untuk itu, perlu diberikannya reward berupa penghargaan sebagai apresiasi kepada dosen yang meluangkan waktu untuk bekerja dalam waktu yang lama disamping Tel-U point dosen yang sudah dijalankan saat ini. Dimensi Meaningfulness berkenaan pertimbangan pendapat karyawan di tempat kerja. Saat ini Telkom University sudah memberikan value tambahan mengenai openness. Namun, penerapan value masih belum optimal bagi karyawan. Untuk mengatasi masalah pada faktor penghargaan perlu diberikan pelatihan terkait value openness. Sistem Pelatihan Tersebut mencakup hal-hal berikut:

a. Analisis Kebutuhan Jenis Pelatihan

b. Analisis Kebutuhan Pelatihan

c. Menentukan Peserta Pelatihan

d. Evaluasi Hasil Pelatihan

Penelitian ini hanya sampai tahap develop, namun untuk rencana pengimplementasian dan 
evaluasi dapat dilakukan berdasarkan program yang dibuat seperti hal berikut:

a. Survei kebutuhan dan identifikasi kebutuhan dapat dilakukan 2 kali dalam satu tahun.

b. Reward diberikan berupa penghargaan kepada dosen yang meluangkan waktu lama untuk bekerja sebagai bentuk apresiasi disamping penerapan Tel-U point dosen saat ini.

c. Melakukan pelatihan mengenai value openness serta memberikan pre-test dan posttest sebelum dan sesudah dilakukannya pelatihan

Untuk tahap evaluasi dapat dilakukan dengan mengukur dampak program peningkatan employee engagement terhadap karyawan, apakah meningkatkan kinerja dan produktivitas karyawan setelah dilakukannya program yang sudah dirancang atau sebaliknya. Hasil penelitian yang dilakukan oleh Triwibisono memiliki satu kesamaan dengan penelitian ini. Hal ini berkaitan dengan dimensi basic need yang berkorelasi dengan keterlibatan karyawan. Dimensi ini berkaitan dengan kebutuhan dasar yang dibutuhkan oleh pekerja dalam menyelesaikan pekerjaannya. Pada penelitian ini dimensi basic need juga memiliki korelasi dengan keterlibatan karyawan (Triwibisono, 2017)

Hasil penelitian yang dilakukan Rifani memiliki dua perbedaan dengan penelitian ini. Pertama, faktor-faktor yang menjadi indikator employee engagement dengan nilai terendah. Pada penelitian Rifani et al. (2016) faktor tersebut terdiri dari career opportunitiess, work tasks dan learning \& development. Sedangkan pada penelitian ini, faktor tersebut terdiri dari materialperalatan, lama bekerja dan penghargaan. Kedua, karena faktor yang memiliki nilai terendah berbeda, maka program perancangan yang dibutuhkan untuk dapat meningkatkan employee engagement pada perusahaan juga berbeda (Rifani et al., 2016). Hasil penelitian yang dilakukan Loice memiliki perbedaan dengan penelitian ini. Hal ini berkaitan dengan tingkat engagement Dosen yang dibagi menjadi 3 yaitu dosen 12 jam, dosen 24 jam dan dosen 36 jam. Pada penelitian ini tingkat engagement yang diukur hanya pada dosen tetap (Loice et al., 2014).

\section{KESIMPULAN}

Telkom University memiliki tingkat engagement sebesar 34\% untuk kategori engaged dan $66 \%$ untuk kategori not engaged berdasarkan pengukuran dengan Metode ADDIE. Peningkatan keterlibatan karyawan pada Telkom University berdasarkan dimensi-dimensi dengan nilai terendah yaitu basic need, spirit dan meaningfulness untuk tiga faktor yang perlu diberikan program usulan peningkatan. Faktor material dan peralatan adalah dengan membuat survei kebutuhan karyawan dan membuat format standar untuk identifikasi kebutuhan karyawan. Faktor bekerja untuk waktu yang lama adalah dengan membuat pengembangan program reward, yaitu memberikan hadiah sebagai bentuk apresiasi bagi dosen yang bekerja dalam waktu yang lamaFaktor penghargaan adalah dengan membuat program pelatihan mengenai value openness, dimana value ini tergolong baru diimplementasikan. Untuk penelitian lanjutan dapat dilakukan pengukuran dengan tenaga penunjang akademik sebagai sampel dari penelitiannya.

\section{DAFTAR PUSTAKA}

Adkins, A. (2014). Majority of U.S. Employees Not Engaged Despite Gains in 2014. https://news.gallup.com/poll/181289/majorit $y$-employees-not-engaged-despite-gains2014.aspx

Albrech, S. L. (2011). Handbook of Employee Engagement: Perspectives, Issues, Research and Practice. Human Resource Management International Digest, 19(7), hrmid.2011.04419gaa.019. https://doi.org/10.1108/hrmid.2011.04419ga a. 019

Hobfoll, S. E. (2001). The Influence of Culture, Community, and the Nested-Self in the Stress Process: Advancing Conservation of Resources Theory. Applied Psychology, 50(3), 337-421. https://doi.org/10.1111/1464-0597.00062

Kaliannan, M., \& Adjovu, S. N. (2015). Effective Employee Engagement and Organizational Success: A Case Study. Procedia - Social and Behavioral Sciences, 172(1), 161-168. https://doi.org/10.1016/j.sbspro.2015.01.350

Kumar, J. A. (2012). Employee Engagement, Saaransh. RKG Journal of Management, 3(2), 81-86.

Kwon, K., \& Kim, T. (2020). An integrative literature review of employee engagement and innovative behavior: Revisiting the JD-R model. Human Resource Management Review, 30(2), 1-20. https://doi.org/10.1016/j.hrmr.2019.100704

Loice, R., Hariandja, J., \& Alfian, A. (2014). Employee engagement index Universitas Katolik Parahyangan. In Research ReportEngineering Science. http://journal.unpar.ac.id/index.php/rekayas a/article/view/767

Mehta, D., \& Mehta, N. K. (2013). Employee engagement: A literature review. Economia. 
Seria Management, 16(2), 208-215. http://management.ase.ro/reveconomia/201 3-2/1.pdf

Pargito. (2010). Perencanaan Pengajaran. Jakarta: Rineka Cipta.

Rawling, R. (2015). Key Drivers for Improving Organisational Performance Annual Australian Centre for Healthcare Why Is It That Some Organisations Excel and Some Are Seemingly.

Rifani, D., Nugraha, F. N., \& Aisha, A. N. (2016). Perancangan Program Peningkatan Employee Engagement Di Pt Xyz Dengan Menggunakan Metode Addie. EProceedings of Engineering, 3(2), 2874-2881. https://libraryeproceeding.telkomuniversity.a c.id/index.php/engineering/article/view/1717

Telkom University. (2019). Nilai Kinerja Individu. Bandung: Telkom University.

Tenaga Menteri dan Transmigrasi Republik Indonesia. (2004). 102/Men/VI/2004 Tentang Waktu Kerja Lembur dan Upah Kerja Lembur. Jakarta. https://jdih.kemnaker.go.id/data_puu/peratur an_file_186.pdf

Triwibisono, C. (2017). Peningkatan Keterlibatan Karyawan melalui Manajemen Sumber Daya Manusia Stratejik, Kepemimpinan Transformasional dan Budaya Organisasi serta Pengaruhnya pada Komitmen Organisasional. Bandung: Unpad Press.

Triwibisono, C., Sule, E. T., Effendi, N., \& Yunizar, N. A. (2017). The influence of strategic human resource management on employee engagement. International Journal of Business and Globalisation, 19(3), 414-432. https://doi.org/10.1504/IJBG.2017.087226 